\title{
POTENSI GOA MARIA SENDANG JATININGSIH SEBAGAI OBJEK WISATA ROHANI DI DAERAH ISTIMEWA YOGYAKARTA
}

\author{
Hery Krestanto \\ Dosen Akademi Pariwisata Yogyakarta \\ email:herychrestanto@ymail.com
}

\begin{abstract}
This research aims to give knowledge about Jatiningsih Sendang Maria Cave as a potential spiritual tourism object, a place of pilgrimage and increasing knowledge of the Christian community about Jatiningsih Sendang Maria Cave. The type of this research is a qualitative research. An observation and interview method is needed to get the data of the research. This research focuses on the potential of Jatiningsih Sendang Maria Cave as a spritual tourism object. The results of this research indicate that the potential of Jatiningsih Sendang Maria Cave as a spiritual tourism object in Yogyakarta, it can be reached by riding various types of vehicles such as motorcycles, cars, tourist buses. Jatiningsih Sendang Maria Cave is located approximately $20 \mathrm{~km}$ to the west of monument Jogja.
\end{abstract}

\section{PENDAHULUAN}

Pariwisata saat ini sudah akrab dikenal oleh setiap orang. Pariwisata adalah suatu industri yang bisa menghasilkan banyak devisa bagi suatu negara. Pariwisata merupakan industri yang menyerap banyak tenaga kerja. Menurut Ali Hasan (2018) bahwa faktor yang menarik wisatawan untuk berkunjung adalah :

1. Keindahan alam, ada beberapa hal yang khusus mengenai keindahan alam. Pertama dari pihak wisatawan tidak perlu pengeluaran biaya, kedua keberagaman di suatu daerah bisa merupakan suatu yang menambah daya tarik dan dapat sebagai bagian pokok dari promosi.

2. Iklim dan cuaca, faktor iklim dan cuaca dapat menarik wisatawan untuk mengunjungi tempat wisata.

3. Kebudayaan, faktor paling menarik bagi wisatawan adalah perbedaan kebudayaan antara tempat asal dan kebudayaan yang dikunjungi.

4. Sejarah. Sumber daya historis dapat dibagi antara lain: perang, agama, perumahan dan pemerintahan. Misalnya wisatawan kadang senang mengunjungi tempat yang digambarkan dalam karya sastra khususnya novel-novel yang pernah mereka baca.

5. Etnicity. Beberapa negara yang pernah menerima banyak imigran sering mengirim anaknya ke negara asal

6. Accesibility merupakan kemampuan untuk mencapai suatu tempat tujuan menurut waktu, biaya, frekwensi, dan keuangan.

Berdasarkan faktor-faktor tersebut maka pariwisata terus dikembangkan oleh pemerintah karena berkembangnya pariwisata maka banyak devisa yang bisa masuk kas negara. Dan dengan devisa yang 
besar maka dapat membantu perubahan ekonomi. Maka untuk mengembangkan pariwisata dikeluarkan peraturan-peraturan, salah satunya pedoman penyelenggaraan Sapta Pesona yang bertujuan untuk meningkatkan kualitas produk dan memperbaiki mutu pelayanan pariwisata nasional.

Adapun Sapta Pesona itu adalah : Pesona Aman, Pesona tertib, Pesona Bersih, Pesona Sejuk, Pesona Indah, Pesona Ramah Tamah, dan Pesona Kenangan. Selain itu melalui peraturan, juga dilakukan melalui ajang promosi. Misal, Visit Indonesian Year, Visit Asian Year, dan pengiriman duta wisata dan duta budaya ke luar negeri serta berbagai ajang promosi dalam negeri merupakan usaha dari pemerintah untuk menarik minat wisatawan baik dari luar negeri maupun dalam negeri.

Namun sejak krisis moneter dan ekonomi yang melanda Indonesia mulai pertengahan 1997 dan diperberat dengan adanya krisis politik yang telah menimbulkan dampak di berbagai sektor kehidupan, dalam hal ini adalah memberikan dampak negatif bagi perkembangan industri pariwisata di Indonesia.

Wisatawan asing menjadi takut berkunjung ke Indonesia karena keamanan yang tidak terjamin. "Sebab untuk menghadirkan bisnis raksasa pariwisata menuntut adanya berbagai jaminan agar lingkungan (baik sosial politik, ekonomi, dan budaya) senantiasa terjamin keamanannya dan berada dalam kondisi bersih. Karena hakikatnya sebagai sebuah industri sangat rentan akan gangguan keamanan".

Pengaruh krisis di Indonesia khususnya dan Asia pada umumnya terhadap kondisi kepariwisataan Indonesia antara lain disebabkan:

1. Sekitar $35 \%$ wisatawan mancanegara yang mengunjungi Indonesia adalah dari negara-negara Asia Timur, padahal selain Indonesia krisis juga melanda di Asia timur

2. Krisis ekonomi di Indonesia di iringi dengan krisis politik dan keamanan

3. Daya beli wisatawan nusantara menurun dengan drastis (Oka Yoeti, 2013)

Dalam kondisi ini, sektor pariwisata diharapkan akan menjadi sumber pertumbuhan paling cepat. Hal ini dikarenakan infrastruktur kepariwisataan tidaklah mengalami kerusakan, hanya saja faktor keamanan yang menyebabkan wisatawan mancanegara mengurungkan kepergiannya ke Indonesia. Hal ini dapat memberikan harapan bahwa kepariwisataan dapat langsung aktif bilamana wisatawan terutama wisatawan nusantara dapat diaktifkan kembali. Walaupun penghasilan seringkali banyak dikaitkan dengan jumlah wisatawan mancanegara, karena menghasilkan devisa, namun wisatawan nusantara sangat mempengaruhi kegiatan kepariwisataan. Pariwisata, selain bisa meningkatkan pertumbuhan ekonomi melaui pendapatan dari devisa yang diterima, juga dapat menciptakann lapangan kerja baru.

Potensi Kepariwisataan Kabupaten Sleman memiliki sejumlah objek dan daya tarik wisata yang bervariasi, tersebar hampir diseluruh Kecamatan serta masing masing objek wisata mempunyai karakteristik dan daya tarik tersendiri. Kondisi tersebut menunjukkan bahwa potensi kepariwisataan mempunyai prospek yang sangat besar untuk dikembangkan dan 
menjadi andalan utama bagi pendapatan daerah. Daya tarik yang ada hampir meliputi seluruh potensi sumber daya alam, sumber daya lingkungan, sosial budaya, sumber daya nilai histories serta sumber daya buatan.

Potensi wisata yang ada di Kabupaten Sleman ini dapat dilihat dari banyaknya objek wisata yang menarik dan memiliki kekhasan tersendiri. Objek wisata yang dimiliki meliputi objek wisata candi, objek wisata alam, objek wisata museum, objek wisata atraksi dan juga desa wisata yang tersebar di berbagai kecamatan dan kabupaten di Yogyakarta. Keseluruhan desa wisata tersebut dikelompokkan menjadi berbagai bagian antara lain desa wisata budaya, desa wisata pertanian, desa wisata agro, desa wisata fauna, desa wisata kerajinan dan desa wisata lereng Merapi. Salah satu objek wisata yang unik adalah Goa Maria Sendang Jatiningsih. Goa Maria Sendang Jatiningsih terletak di dusun jitar, pingitan paroki klepu daerah Istimewa Yogyakarta.

\section{LITERATURE REVIEW}

\section{Pengertian potensi wisata}

Potensi wisata adalah segala sesuatu yang terdapat di daerah tujuan wisata dan merupakan daya tarik agar orang- orang mau berkunjung ketempat tersebut. Potensi wisata dibagi menjadi 3 macam, yaitu potensi alam, potensi budaya, potensi manusia (Oka Yoeti, 2006)

a Potensi Alam

Potensi alam adalah keadaan dan jenis flora fauna suatu daerah. Klebihan dan keunikan yang dimiliki oleh alam jika dikembangkan dengan memperhatikan keadaan lingkungan sekitarnya niscaya akan menarik wisatawan untuk berkunjung ke objek tersebut.

b Potensi budaya

Potensi budaya adalah semua hasil cipta, rasa dan karsa manusia baik berupa adat istiadat, kerajinan tangan, kesenian, peninggalan bersejarah nenek moyang.

c Potensi manusia

Manusia juga memiliki potensi yang dapatdi gunakan sebagai daya tarik wisata lewat pementasan tarian dan pementasan seni budaya suatu daerah.

2. Pengertian Pariwisata

Menurut Undang-Undang Republik Indonesia Nomer 10 tahun 2009, pariwisata adalah berbagai macam kegiatan wisata dan di dukung berbagai fasilitas serta layanan yang disediakan oleh masyarakat, pengusaha dan pemerintah.

Menurut World Trade Organization (WTO) dalam buku Ismayanti (2010) mengung-kapkan pariwisata diartikan sebagai kegiatan manusia yang dilakukan perjalanan dan tinggal di daerah tujuan diluar lingkungan kesehariannya.

\section{Jenis Pariwisata}

Menurut Undang-Undang Nomer 10 tahun 2009 jenis pariwisata dibedakan menjadi tiga kelompok besar yaitu:

a. Wisata budaya (cultural tourism) adalah jenis wisata yang memanfaatkan potensi hasil budaya manusia sebagai objek dan daya tariknya. Jenis wisata budaya meliputi:

1) Wisata cagar budaya/arkeologis (candi-candi, situs-situs purbakala)

2) Wisata histori/sejarah (peninggalan bekas bersejarah, kraton, musium) 
3) Wisata religius (candi borobudur, prambanan, pura, masjid, candi hati kudus ganjuran, makam orang suci/ besar)

4) Wisata seni (wayang kulit, salawatan, balet, ramayana, kethoprak, dolalak, kudalumping)

5) Wisata kerajinan (batik, topeng, gerabah, kerajinan perak kota gede)

6) Wisata boga (makanan tradisional seperti getuk magelang, geplak bantul, lumpia semarang, wingko babat semarang)

7) Wisata ritual/upacara tradisional (sekaten, grebeg, labuhan, saparan, malam satu suro, sedekah laut)

b. Wisata Alam (natural tourism) adalah jenis wisata yang memanfaatkan potensi alam sebagai objek daya tariknya. Jenis wisata alam meliputi:

1) Wisata dataran tinggi (hawa sejuk, lingkungan alam, dan peman-dangan indah)

2) Wisata cagar alam (dunia flora dan fauna yang dilindungi perilaku kehidupan satwa)

3) Wisata hutan (hutan lindung, taman nasional)

4) Wisata goa (goa kiskendo, goa selarong)

5) Wisata tirta (sungai pindul, sungai elo, sungai progo)

c. Wisata minat khusus (special interest tourism) adalah jenis wisata yang memanfaatkan potensi khusus sebagai objek daya tariknya. Jenis wisata khusus ini meliputi : Wisata konvensi, Wisata olah raga, Wisata industri, Wisata kesehatan, Wisata bulan madu, Wisata kampus

\section{METODE PENELITIAN}

Metode penelitian tentang potensi Goa Maria Sendang Jatiningsih sebagai objek wisata rohani di Daerah Istimewa Yogyakarta menggunakan penelitian deskriptif kualitatif. Teknik pengumpulan data bersumber dari data primer yang merupakan informasi yang diperoleh dari sumber- sumber primer (Sugiyono, 2017)

1. Pengamatan langsung (direct observation)

Metode observasi yaitu cara memperoleh data yang dilakukan dengan cara mengamati dan mencatat secara secara langsung gejala- gejala yang diteliti. Penulis mendatangi langsung Goa Maria Sendang Jatiningsih supaya peneliti dapat melihat keadaan yang ada di Goa Maria Sendang Jatiningsih.

2. Wawancara langsung (direct Interview)

Metode Wawancara adalah proses tanya jawab dalam penelitian yang berlangsung secara lisan. Penulis melakukan wawancara terhadap terhadap pihak yang terkait yaitu pihak pengelola Goa Maria Sendang Jatiningsih.

3. Dokumentasi (Documentation)

Dokumentasi ini dilakukan guna mendapatkan foto atau gambar Goa Maria Sendang Jatiningsih.

\section{HASIL PENELITIAN DAN \\ PEMBAHASAN}

\section{Sejarah Goa Maria Sendang Jatiningsih.}

Perjalanan waktu telah menghantarkan Goa Maria Sendang Jatiningsih yang berarti sumber air dari rahmat Tuhan yang sungguh-sungguh mendatangkan kedamaian, ini menjadi salah satu pilihan bagi siapa saja yang ingin 
melepaskan dahaga rohaninya. Awal mula pembangunan Goa Maria Sendang Jati ningsih yang semula bernama Sendang Pusung (Sing ngapusi busung = siapa yang berbohong akan terkena ulahnya) Goa Maria Sendang Jatiningsih di bangun dari perkembangan gereja katolik di daerah klepu, khususnya di dusun jitar pingitan daerah Istimewa Yogyakarta.

Goa Maria Sendang Jatiningsih berada di bawah rimbunan pepohonan jati di dusun Jitar Pingitan. Masyarakat dusun Jitar Pingitan pada mulanya belum memeluk satu agama. Mereka masih abangan atau boleh dibilang masih menganut kejawen. Namun sekitar tahun 1950-an anak-anak mereka yang memeluk agama katholik sukses dalam pendidikan dan mempunyai pekerjaan yang mapan. Rupanya kesuksesan anak-anak ini menjadi daya tarik tersendiri bagi orangtua mereka untuk kemudian menjadi katholik.

Kisah itu bermula dari dibaptisnya FX Dikin di gereja St Petrus dan Paulus Klepu pada Desember 1952. Dikin ketika itu masih duduk di kelas V SD Kanisius Ngapak. Setahun kemudian tahun 1953, bulan April, jejak Dikin disusul empat rekannya yaitu Ignasius Tentrem, P. Sapardi, B. Semin, dan Taryono. Mereka inilah yang menjadi pionir berkembangnya agama katholik di dusun Jitar, pingitan daerah Istimewa Yogyakarta. Setelah dibaptis, P. Sapardi mempelopori berdirinya lingkungan jitar pingitan.

Pelajaran agama katholik dilakukan Sapardi setiap malam Jumat, lambat laun umat di lingkungan semakin bertambah. Berbagai kegiatan kesenian tradisional seperti wayang orang, ketoprak, karawitan, tari kreasi baru, bahkan selawatan merupakan sarana pewartaan yang dimanfaatkan para muda-mudi ketika itu.
Mereka tak segan-segan menambah label katholik di belakang nama kegiatan mereka, seperti wayang orang katholik, ketoprak pemuda katholik. Umat katholik semakin berkembang di dusun jitar, masyarakat jitar belum mempuyai tempat ibadah sehingga Ignatius Purwowidono terdorong untuk menghibahkan tanahnya seluas 200- $\mathrm{m}^{2}$ yang berada disebelahan rumahnya untuk didirikan kapel bagi umat lingkungan jitar pingitan.

Tanah hibahan Ignatius Purwowidono itu ternyata tidak jadi untuk kapel. Dikarenakan menurut pastor paroki ketika itu jarak antara dusun jitar pingitan dan gereja paroki hanya $2,1 / 2-\mathrm{km}$. Ignatius Purwowidono kemudian menukarkan tanah seluas $200-m^{2}$ di sebelah rumahnya dengan tanahnya yang terletak di tepi Kali Progo seluas $800-\mathrm{m}^{2}$. Dengan swadaya umat perlahan-lahan membangun tempat ibadat. Pada tanggal 1-Mei-1986 umat katolik jitar mebuat Goa Maria dengan cara swadaya mereka mendatangkan batu gua putih yang banyak berlubang dari Gunung kidul. Patung Bunda Maria dibuat seorang pematung dari Muntilan.

Pada tanggal 8 September 1986 Patung Bunda Maria diberkati Romo Mardi Kartono SJ. Sejak itulah Goa Maria Sendang Jatiningsih mulai ramai dikunjungi banyak peziarah. Pada hari minggu tanggal 27 Oktober 2002 umat Paroki Klepu mengadakan misa bersama Mgr J. Sunarka SJ di Goa Maria Sendang Jatiningsih sebagai ungkapan syukur atas ditemukannya sumber mata air baru yaitu Tirto wening banyu panguripan = air kehidupan, letaknya persis di belakang Goa Maria. Goa Maria Sendang Jatiningsih sebagai tempat berdoa atau melakukan perenungan. Tempat ini jauh dari polusi udara dan hiruk pikuk keramaian, suara 
kendaraan pun hampir tidak terdengar, yang ada adalah suasana hening yang mendalam.

Goa Maria Sendang Jatiningsih ini berada di tepi Sungai Progo dengan rerimbunan pohon-pohon jati, suasana tenang dan damai membuat para peziarah dapat berdoa dengan khusuk karena terletak di pinggiran sungai progo, bunyi percikan air sangat menambah hikmatnya suasana. Di Goa Maria Sendang Jatiningsih, Anda akan menemukan ketenangan jiwa dan raga.

Di Goa Maria Sendang Jatiningsih juga terdapat sendang (mata air) yang airnya dialirkan melalui kran-kran yang dipasang di tempat ini. Air yang mengalir di kran ini disebut juga Tirta Wening Banyu Panguripan. Biasanya peziarah menggunakan tirta wening ini untuk mencuci muka bahkan ada pula yang membawa pulang ke rumah. Sebuah salib besar diletakkan di samping Goa Maria, sedangkan pendopo tepat di depan pelataran doa dapat

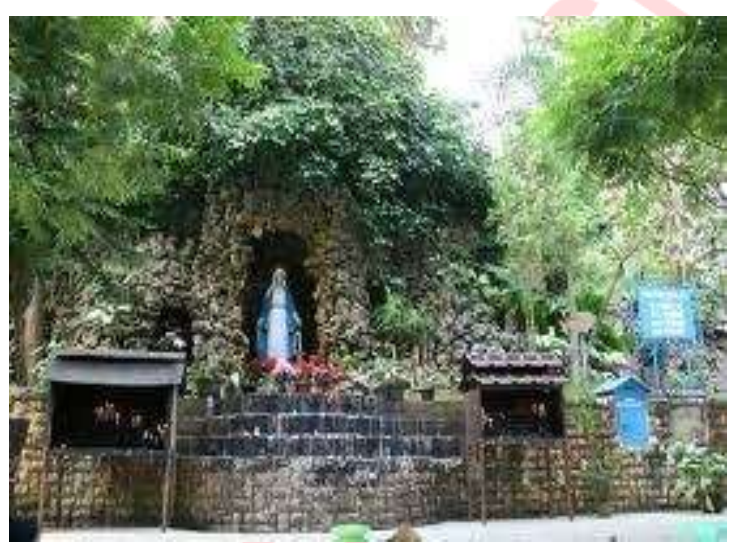

Gambar 1. Goa Maria Sendang

Jatiningsih

\section{Pembahasan}

Analisis potensi Goa Maria Sendang Jatiningsih sebagai wisata rohani.

\section{Sapta pesona}

Sapta pesona merupakan kondisi yang harus diwujudkan dalam rangka menarik digunakan sebagi tempat istirahat. Goa Maria Sendang Jatiningsih menyediakan pelayanan doa dan ekaristi pada Bulan Maria yaitu pada bulan Mei dan Oktober, sedangkan untuk Doa Novena diadakan setiap malam Jumat kliwon di sepanjang tahun.

Perayaan ekaristi dimulai pada malam hari dan dilanjutkan dengan penghormatan kepada Sakramen Maha Kudus. Goa Maria Sendang Jatiningsih memiliki beberapa fasilitas penunjang yang dapat digunakan oleh peziarah. Fasilitas tersebut antara lain toilet umum yang tersebar di pelataran maupun komplek sendang, kios suvenir dan makanan, tempat parkir yang luas, aula St. Aloysius, rute jalan salib, pendopo-pendopo yang digunakan untuk beristirahat atau berdoa, serta kapel tebuka yang sering digunakan untuk kegiatan misa. Penginapan pun disediakan dilokasi ini sebagai tempat retreat atau rekoleksi.

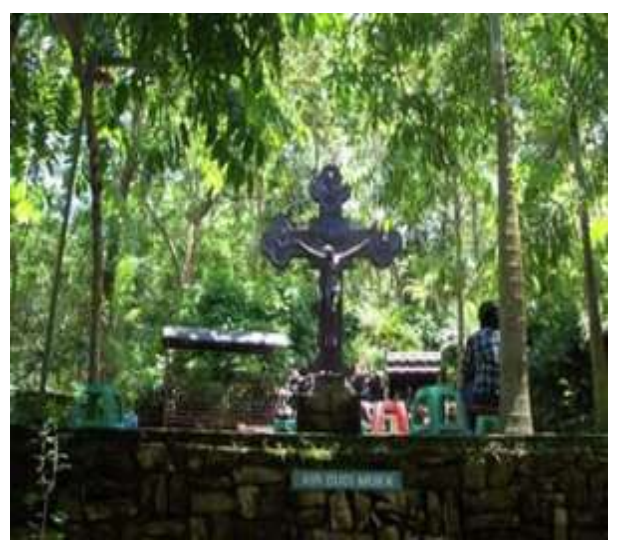

Gambar 2. Salib minat wisatawan berkunjung ke suatu daerah atau wilayah dinegara kita. Kita harus menciptakan suasana indah mempesona dimana saja dan suasana yang menarik dan nyaman, wisatawan akan betah tinggal lebih lama, merasa puas atas 
kunjungannya dan memberikan kenangan yang indah dalam hidupnya. Sapta pesona terdiri dari tujuh unsur yaitu:

\section{Aman}

Warga di sekitar Goa Maria Sendang Jatiningsih menjaga keamanan wisatawan bekerjasama dengan aparat poslek moyudan. Aman yaitu suatu kondisi dimana wisatawan dapat merasakan dan mengalami suasana yang aman, bebas dari ancaman, gangguan, serta tindak kekerasan dan merasa terlindungi, bebas dari:

a Kekerasan, tindak kejahatan, ancaman seperti kecopetan, pemerasan, penodongan, penipuan.

b Terserang penyakit menular dan penyakit berbahaya lainnya.

c Kecelekaan yang disebabkan oleh alat perlengkapan dan fasilitas yang kurang baik, seperti kendaraan, peralatan untuk makan dan minum,dan rekreasi.

d Gangguan oleh masyarakat antara lain berupa pemaksaan oleh pedagang asongan, tangan jahil, ucapan dan tindakan serta prilaku yang tidak besahabat dan lain sebagainya.jadi aman terjamin keselamatan jiwa dan fisik, termasuk milik (barang) wisatawan.

\section{Tertib}

Warga di sekitar Goa Maria Sendang Jatiningsing berperilaku tertib mengikuti norma - norma yang berlaku seperti tidak kebut- kebutan di jalan, tidak adanya anarkis, tidak main hakim sendiri. Tertib yaitu kondisi yang mencerminkan suasana tertib dan teratur serta disiplin dalam semua segi kehidupan masyarakat baik dalam hal lalu lintas kendaraan, penggunaan fasilitas maupun dalam berbagai perilaku masyarakat lainnya, misalnya: a Lalu lintas tertib, teratur dan lancar

b Tidak ada nampak orang yang berdesakan atau berebut mendapatkan atau membeli sesuatu yang diperlukan

c Bangunan dan lingkungan ditata teratur dan rapi.

d Informasi yang benar dan tidak membingunkan.

\section{Bersih}

Warga di sekitar Goa Maria Sendang Jatiningsih siap menjaga kebersihan lingkungan. Bersih yaitu kondisi yang memperlihatkan sifat bersih dan higienis baik keadaan lingkungan, sarana pariwisata, alat perlengkapan pelayanan maupun manusia yang memberikan pelayanan tersebut. Wistawan akan merasa betah dan nyaman bila berada di tempat-tempat yang bersih dan sehat seperti:

a Lingkungan yang bersih baik dirumah sendiri maupun ditempat-tempat umum, restoran, angkutan umum, tempat rekreasi, tempat buang air besar/besar.

b Sajian makanan dan minuman bersih dan sehat.

c Penggunaan dan penyediaan alat pelerlengkapan yang bersih.

d Pakaian dan penampilan petugas bersih, rapi dan tidak mengeluarkan bau yang tidak sedap.

\section{Sejuk}

Warga di sekitar Goa Maria Sendang Jatiningsih ikut menjaga memelihara tanaman/pepohonan di area umum. Sejuk berarti terciptanya suasana yang segar, sejuk serta nyaman yang dikarenakan adanya penghijauan secara teratur dan indah baik dalam bentuk taman maupun penghijauan di setiap lingkungan tempat tinggal kita dengan cara: 
a Turut serta aktif memelihara kelestarian lingkungan dan hasil penghijauan yang telah dilakukan masyarakat ataupun pemerintah.

b Berperan secara aktif untuk menganjurkan dan memelopori agar masyarakat setempat melaksanakan kegiatan penghijauan dan memelihara kebersihan, menanan berbagai tanaman dihalaman rumah masingmasing baik untuk hiasan maupun tanaman yang bermanfaat bagi rumah tangga, dihalaman sekolah dan lain sebagainya.

c Membentuk perkumpulan yang bertujuan mememlihara kelstarian lingkungan.

d Menghiasi ruang belajar/kerja, ruang tamu, ruang tidur dan tempat lainnya dengan aneka tanaman penghias atau penyejuk.

e Memprakarsai berbagai kegiatan dan upaya lain yang dapat membuat lingkungan hidup kita menjadi sejuk, bersih, segar dan nyaman.

\section{Indah}

Warga disekitar Gua Maria Sendang Jatiningsih siap menjaga keasrian lingkungan. Indah yaitu kondisi yang mencaerminkan penataan yang teratur, tertib dan serasi baik mengenai prasarana, sarana, penggunaan tata warna yang serasi, selaras dengan lingkungannya serta menunjukkan sifat-sifat kepribadian nasional. Indah yang selalu sejalan dengan bersih dan tertib dan tidak terpisahkan dari lingkungan hidup baik berupa ciptaan Tuhan Yang Maha Esa maupun hasil karya manusia. Karena itu kita wajib memelihara lingkungan hidup agar lestari dan dapat dinikmati oleh manusia.

\section{Ramah Tamah}

Warga disekitar Goa Maria Sendang Jatiningsih bersikap ramah jika bertemu dengan wisatawan dan besedia membantu jika wisatawan membutuhkan informasi. Ramah Tamah yaitu sikap dan prilaku masyarakat yang ramah dan sopan dalam berkomunikasi, memberikan pelayanan serta ringan tangan untuk membantu tanpa pamrih. Ramah tamah merupakan watak dan budaya bangsa Indonesia pada umumnya, selalu menghormati tamunya dan dapat menjadi tuan rumah yang baik. Sikap ramah tamah ini merupakan daya tarik bagi para wisatawan.

\section{Kenangan}

Warga disekitar Goa Maria Sendang Jatiningsih siap membuat wisatawan senang sehingga ada kenangan yang di bawa pulang. Kenangan yaitu kesan yang menyenangkan dan akan selalu di ingat. Kenangan dapat berupa yang indah dan menyenangkan akan tetapi dapat pula yang tidak menyenangkan. Kenangan yang ingin diwujudkan dalam ingatan dan perasaan wisatawan dari pengalaman berwisata di Indonesia dengan sendirinya adalah yang menyenangkan. Kenangan yang indah ini dapat pula di ciptakan dengan:

a Akomodasi yang nyaman, bersih dan pelayanan yang cepat, tepat dan ramah.

b Atraksi-atraksi budaya yang khas mempesona.

c Jenis makanan khas daerah yang lezat dengan penampilan dan penyajian yang menarik dan higienis.

d Cendera mata yang merupakan ciri khas daerah dengan tampilan yang indah dan harga yang murah. 
KESIMPULAN, KETERBATASAN DAN REKOMENDASI

\section{Kesimpulan}

1. Goa Maria Sendang Jatiningsih mempuyai potensi sebagai obyek wisata rohani di daerah Istimewa Yogyakarta

2. Hal- hal yang medukung potensi Goa Maria Sendang Jatingsih sebagai obyek wisata rohani antara lain : akses jalan yang menuju Gua Maria Sendang Jatiningsih sudah di aspal dan dapat dilalui berbagai jenis kendaraan seperti sepeda motor, mobil, bus pariwisata.

\section{Keterbatasan}

Dalam melakukan penelitian ini, peneliti berusaha semaksimal mungkin namun terdapat keterbatasan. Keterbatasan yang menjadi kendala bagi peneliti antara lain:

1. Keterbatasan untuk mendapatkan sumber data informasi

2. Keterbatasan dari penilitian menyangkut biaya, kemampuan dan waktu

3. Peneliti hanya meneliti potensi wisata rohani, padahal masih banyak potensi wisata lainya

\section{Rekomendasi}

Dengan diperoleh hasil penelitian ini, maka peneliti rekomendasi tentang:

1. Goa Maria Sendang Jatiningsih dapat dijadikan sebagai tempat wisata rohani

2. Dapat di gunakan sebagai bahan pertimbangan bagi peneliti lain yang berminat terutama berkaitan dengan potensi wisata rohani

\section{REFERENSI}

Ali Hasan, 2018. Pengantar Pariwisata. Yogyakarta: Center for Academic Publihing Service

Anonim, 2009. Undang- Undang RI No 10 Tentang Kepariwisataan

Ismayanti, 2010. Pengantar Pariwisata. Jakarta: Gramedia Widiasarana Indonesia

Oka A.Yoeti, 2013. Pemasaran Pariwisata. Bandung: CV Angkasa

James Spillane, 1991. Ekonomi Pariwisata, Sejarah dan Prospeknya. Yogyakarta: Kanisius

Oka A.Yoeti, 2006. Pariwisata budaya masalah dan solusinya. Jakarta: Pradnya Paramita.

Sugiyono, 2017. Metode penelitian kualitatif. Bandung : Alfabeta. 